\title{
재활승마가 노인의 균형과 노인 삶의 질척도에 미치는 영향
}

\author{
김은자 ${ }^{1}$, 김명준 $^{1}$, 이문하 $^{2}$, 김대훈 $^{* 1}$ \\ ${ }^{1}$ 경동대학교 물리치료학과, ${ }^{2}$ 한국재활승마센터
}

Effects of Rehabilitation Horse Riding on the Balance and Geriatric Quality of Life Scale of the Elderly.

Eun-Ja Kim, PT, PhD ${ }^{1}$, Myung-Joon Kim, PT, PhD ${ }^{1}$, Moon-Ha Lee ${ }^{2}$, Dae-Hun Kim, PT, PhD ${ }^{* 1}$

${ }^{*}$ Dept. of Physical Therapy, Kyungdong University,

${ }^{2}$ Korea riding for the disabled education center

Purpose The purpose of this study was to investigate the effect of rehabilitation horse riding exercise on the balance and Geriatric Quality of Life Scale (GQOL) of the elderly. Methods The subjects were 14 elderly males who consisted of 7 in the experimental group and 7 in the control group. The subjected performed rehabilitation horse riding exercise twice a week for 12 weeks. For balance measurements, left-right and anterior-posterior weight bearing, and BBS were tested using GymPlate. In addition, the GQOL was evaluated. Results The results of this study show that in the experimental group, there were significant differences in balance ability and GQOL after the rehabilitation horse riding exercise $(\mathrm{P}<0.01)$, but there was no significant difference in the control group $(\mathrm{P}>0.05)$. Furthermore, the experimental and control groups showed significant differences in balance ability and GQOL $(\mathrm{P}<0.01)$. Conclusion Rehabilitation horse riding exercise is effective in improving the balance ability of the elderly, which also had an effect on the GQOL.

Key word Horse riding, Balance, GQOL, Elderly, weight distribution

Corresponding author Dae-Hun Kim (vertetrac@kduniv.ac.kr)

Received date 12 July 2018

Revised date 29 September 2018

Accepted date 06 October 2018

\section{I. 서 론}

노인 인구는 의학과 과학기술의 발전으로 증가하여 세계적으 로 고령화 사회에 접어 들었고 사회적. 경제적 안정 속에서 태어난 세대가 노인기에는 심각한 고령화가 될 것으로 예상하 고 있다. 특히 우리나라의 베이비부머 세대의 예비 노인층은 이전의 노인층과 다르게 전반적 삶의 질이 높아졌다. 그리고 건강에 대한 관심이 높아져 건강이 삶의 질에 중요한 영향을 미친다고 여기며, 노인기의 길어진 수명을 건강하게 유지하기 위한 운동 프로그램 요구가 증가 하였다. ${ }^{1)}$

노인의 생리학적 변화 중 골격근육량의 감소로 인한 근감 소증이 발생한다. 노화로 인한 근감소증은 신체기능의 장애와 사망의 위험을 증가시킨다. 우리나라 사람들은 서양인에 비해 상대적 마른 체형이어서 적은 양의 근육이 소실 되어도 정상 근육양이 역치 이하가 된다. ${ }^{2}$ 노인의 근력유지는 순발력과 민 첩성이 관련된 여가활동과 선 자세 유지와 보행 하는 동안 주 어진 환경에서 균형을 유지하여 독립적 일상생활활동을 할 수

http:dx.doi.org/10.17817/2018.09.29.111299
있도록 한다. 따라서 근력과 균형 향상 유지 위한 지속적이고 규칙적 운동이 중요하다. ${ }^{3)}$

노화에 따른 근골격계와 신경계의 퇴행성 변화로 낙상 위 험 있는 노인을 대상으로 재활승마 운동은 매우 유용하다. 말 을 타는 동안 기계적 자극이 근골격계와 신경계 자극하여 근 활성도를 증가시키며, 특히 말의 움직임에 따른 기승자의 체 간 움직임은 전정계를 자극하여 균형 운동에 효과가 있고 말 을 조정하는 동안 상지의 움직임과 등자의 하지 움직임으로 신체활동을 증가 시킬 수 있다. ${ }^{4)}$ 특히 등자 위에서 선 자세 유지는 엉덩관절과 무릎관절의 근육을 강화 시키고 상지의 외 전과 체간의 회전 움직임으로 체간근이 강화되어 균형이 증가 된다. ${ }^{\text {) }}$

말은 운동수단으로 사용되었으나 1670년대 영국에서 환자 를 대상으로 장애 극복 치료에 사용되기 시작했다. 재활승마 는 신체적. 정신적 장애를 극복하여 삶의 질 향상 위한 목적 으로 다양한 질환에 적용되고 있다. 말을 매개로 치료에 적용 하므로 기승자의 자신감 회복과 정서적 안정에 많은 도움이 된다. ${ }^{()}$기승자는 말을 타는 동안 머리, 몸통, 팔, 다리의 움직 
임으로 말의 속도를 조정하고 제어 하면서 신체 균형을 유지 한다. 그리고 말과의 의사소통을 하면서 인지능력 향상에도 영향을 미친다. ${ }^{7)}$ 재활승마의 운동강도는 유산소 운동과 같은 효과가 있어서 염증지표를 감소시키어 운동 후 발생하는 피로 도를 적게 하여 다양한 질환의 환자에게 적용 할 수 있으며, ${ }^{8)}$ 척수손상, 뇌졸중, 다발성 경화증, 뇌성마비, 근이영양증, 정신 지체 등 다양한 환자를 대상으로 적용된다. 특히 노인을 위한 재활승마 운동은 근력강화, 자세조절 향상, 다양한 감각 자극, 관절운동 범위가 증가되며 자존감 증가, 감정조절, 삶의 만족 도 등이 증가된다. ${ }^{5)}$ 국내에서 재활승마는 짧은 역사를 가지고 있으나 장애인을 대상으로 활성화 되었다. 승마는 신체의 근 육과 관절을 이용하는 운동으로 신체기능 향상과 사회성 발달 로 삶의 질을 향상시킨다. ${ }^{6}$ 실외에서 실시하는 재활승마는 뇌 성마비 아동을 대상으로 한 연구는 많으나 노인을 대상으로 재활승마는 실내에서 승마기계를 이용하여 많이 실시하고 있 다. 노화에 따른 신체기능 변화는 다양한 질병을 발생시키며, 근골격계와 신경계의 변화는 낙상과 밀접한 관계가 있다. 낙 상은 노인의 신체적, 정신적 장애를 발생시키고 독립적 일상 생활활동에 영향을 미치고 삶의 질을 떨어뜨리게 된다. 따라 서 노인의 균형능력 유지와 향상을 위한 운동은 매우 중요하 다. 말을 매개로 하는 재활승마는 균형과 삶의 질 향상에 효 과가 있으나 노인을 대상으로 한 연구는 부족하다. 이에 본 연구는 노인을 대상으로 재활승마가 균형과 삶의 질척도에 미 치는 영향을 알아보고자 하였으며, 노인을 대상으로 적용되는 재활승마의 임상적 근거에 도움이 되고자 한다.

\section{II. 연구방법}

\section{1. 연구기간 및 대상자}

본 연구의 대상자는 강원도 고성군에 위치한 $\mathrm{K}$-승마교육센터 에서 65 세이상 노인을 대상으로 하였으며, 연구 대상자의 선정 기준은 지역에서 독립적 일상생활이 가능한 자로 하였고, 중추 신경계 질환과 정형외과적 질환이 있는 자는 제외 시켰다. 연 구의 대상자는 총 21 명 이었으며, 컴퓨터 추첨을 통해 실험군 11 명, 대조군 10 명 선정하였으나 연구 기간 중 탈락자가 발생 하여 실험군 7명, 대조군 7명 총 14 명을 대상자로 하였다. 연 구 기간은 2017년 5월부 7월까지 시행하였다, 본 연구의 대상 자에게 연구의 목적을 설명한 후 자발적 참여 동의 의사가 있 는 자를 선정하였고 일반적 특성은 (table 1)과 같다.

\section{2. 중재방법}

본 연구의 실험군은 주2회, 12 주 재활승마 훈련을 실시하였 다. 재활승마 훈련을 실시하기 전 보호용 헬멧과 조끼를 착용 하였고, 낙마예방을 위해 승마교육센터에서 교육을 담당하는 보조자의 도움을 받아 중재를 하였다. 승마 중재는 준비운동 5 분, 승마 20 분, 마무리 운동 5 분 총 30 분 실시하였다. 준비 운동과 마무리 운동 시간을 이용하여 말과 상호작용을 하여 흥미를 유발할 수 있도록 하였다(Table 2).

본 연구의 대조군은 주 2 회, 12 주 동안 신장운동, 근력강화 운동 30 분 실시하였고, 건강관련 교육과 상담을 실시하여 중 도 탈락자 최소화 하도록 하였다.

Table 1. The general and clinical characteristics of the subjects

\begin{tabular}{cccc}
\hline Variables & Experimental group $(\mathrm{n}=7)$ & Control group $(\mathrm{n}=7)$ & $\mathrm{P}$ \\
\hline Gender(male/female) & $7 / 0$ & $7 / 0$ & 1.000 \\
Height $(\mathrm{cm})$ & $168.28 \pm 6.47$ & $169.85 \pm 2.79$ & 0.606 \\
Weight $(\mathrm{kg})$ & $65.14 \pm 5.30$ & $70.14 \pm 2.26$ & 0.062 \\
age(year) & $70.14 \pm 3.12$ & $70.71 \pm 2.36$ & 0.748 \\
\hline
\end{tabular}

Table 2. Horse riding exercises

Program

warm-up

Horse riding

20minute

5 minute warm-down

\section{Horse riding contents}

sitting on horse, using proper posture take horse by the reins standing in the stirrups riding forwards riding without stirrups riding independently maneuvering the horse in a fiure eight pattern on flat ground stretching exercises 


\section{3. 측정도구}

\section{1) 정적균형 검사}

정적균형 검사는 Gym-Plate(TECHNO CONCEPT, France) 장비를 사용하였다. 이 측정장비는 발판의 왼쪽, 오른쪽, 앞쪽, 뒤쪽의 독립적인 힘판으로 되어 있으며, 발판은 발바닥 수직 압력을 측정할 수 있다. 왼쪽-오른쪽과 앞쪽-뒤쪽 대각선으로 신체 압력 중심의 이동 정도를 합산하여 수량화 한다. 발판의 USB가 컴퓨터와 연결되어 있어 Gym-Plate 소프트웨어 프로 그램이 자동 분석을 해준다. 왼쪽-오른쪽 체중지지도 분포와 앞쪽-뒤쪽 체중지지도 분포는 $50 \%$ 가까울수록 체중지지가 대 칭을 의미한다. 체중지지도는 $50 \%$ 보다 적은 값을 선택하였 으며, $50 \%$ 큰 값은 $100 \%-50 \%$ 차이 값을 데이터 값으로 산 출하였다. 대상자는 눈을 뜬 상태에서 전방에 표시한 곳에 시 선을 유지하고 바로 선 자세에서 60 초 유지하여 측정하였다. 본 연구에서 측정 장비로 사용한 Gym-Plate의 신뢰도 분석 을 하였으며 눈을 뜬 상태에서 체중지지 신뢰도 분석한 결과 ICC $=0.860$ 이었다.

\section{2) Berg Balance Scale(BBS)}

노인의 기능적 동적 균형 측정을 위해 앉기, 선 자세, 자세 변 화 등 3 개 영역으로 구성하여 5점 척도, 14 개 항목으로 총 56점의 측정 도구이며, 점수가 높을 수록 균형 유지 능력이 좋은 것으로 평가한다. 균형 측정 위해 step stool, 침대, 손 잡이 있는 의자, 줄자, 초 시계를 사용 하였다.

3) 노인 삶의 질 척도(Geriatric Quality of Life scale, GQOL) 노인의 삶의 질 측정하는 도구이며, 이 도구는 신체, 심리적 건강, 일상생활 독립수준, 사회 관계, 주거 환경, 종교 등의 23 개 문항과 전반적 건강과 삶의 만족도 관련 2 개 문항을 포 함하여 총 25 개 문항으로 구성 되었으며, 만족하지 않는다 1 점, 보통이다 2점, 만족한다 3점, 아주 만족한다 4점 척도이고 자기 보고식이다. 총점의 범위는 25 100점이다. 이 평가도구 의 신뢰도는 0.91 이다. $^{9)}$

\section{4. 분석방법}

본 연구의 통계는 SPSS version 18 을 이용하여 평균과 표준 편차를 산출하였다. 연구 대상자의 일반적 특징은 기술통계를 사용하였고, 실험군과 대조군의 차이는 독립 $\mathrm{t}$ 검정을 실시하 였다. 실험군과 대조군의 중재 전, 후 비교는 비모수 검정의 Mann-Whitney test 실시하였고 집단 내 비교는 Wilcoxon's signed-rank test 실시하였다. 자료의 모든 통계적 유의 수준 은 0.05 로 하였다.

\section{5. 연구결과}

1) 중재 전과 중재 후 실험군과 대조군의 균형과 노인 삶의 질 척 도 변화 비교 실험군의 중재 전과 후의 왼쪽-오른쪽 체중지지도, 앞쪽-뒤쪽 체중지지도 변화 비교에서 유의하게 증가하였으나 $(\mathrm{p}<0.01)$, 대조군의 중재 전과 후의 왼쪽-오른쪽 체중지지도, 앞쪽-뒤쪽 체중지지도 변화 비교에서 유의한 차이가 없었다 $(\mathrm{p}>0.05)$. $\mathrm{BBS}$ 도 실험군은 중재 전과 후 변화 비교에서 유의하게 증가 하였으나 $(\mathrm{p}<0.01)$, 대조군은 유의한 차이가 없었다 $(\mathrm{p}>0.05)$. 노인 삶의 질척도도 실험군은 중재 전과 후 변화 비교에서 유 의하게 증가하였으나 $(\mathrm{p}<0.01)$, 대조군은 유의한 차이가 없었 다 $(\mathrm{p}>0.05)($ Table 3$)$.

\section{2) 실험군과 대조군의 균형과 노인 삶의 질척도 변화 비교} 실험군과 대조군의 중재 후에서 중재 전 차이 값 비교에서 실 험군이 대조군 보다 왼쪽-오른쪽 체중지지도, 앞쪽-뒤쪽 체중 지지도와 $\mathrm{BBS}$, 노인의 삶의 질척도에서 유의한 차이가 있었 다 $(\mathrm{p}<0.01)($ Table 3$)$.

\section{III. 고찰}

본 연구는 노인을 대상으로 재활승마 운동을 실시 한 후 균형 과 노인 삶의 질척도에 미치는 영향을 알아보고자 하였다. 재 활승마 운동은 노인의 균형 향상과 노인 삶의 질척도에 긍정 적 영향을 미치는 것으로 나타났다.

재활승마 운동은 기승자가 좌, 우, 앞, 뒤쪽과 수직 축 방 향으로 머리와 몸통의 움직임을 하는 동안 전정계와 고유수용 성감각의 자극이 지속적으로 주어지며, 이러한 자극이 자세유 지에 안정성을 제공 한다. ${ }^{10)}$ 그리고 말을 타는 동안 기승자는 인간의 가속과 감속의 보행 경험을 하게 되고 다양한 감각 입 력과 운동의 효과가 나타난다. 말 위에서 신체 움직임은 중력 방향에서 체간근을 사용하게 되며, 지면에서 정상 보행하는 동안 체간근 사용하는 것보다 더 많은 근활성 효과가 나타난 다. 따라서 자세조절 능력이 저하되어 이동에 어려움이 있는 운동치료 방법으로 적절하다. ${ }^{11}$

노인을 대상으로 재활승마 운동을 실시한 결과 체간 안정 성과 관련된 항중력근의 활성도와 안정성 한계 $(\mathrm{LOS})$ 가 증가 하였다. 이러한 결과는 신경계와 근골격계의 협응 능력과 정 위반응 증가에 의한 것이며, 노인의 낙상 예방을 위한 균형 훈련으로 매우 효과적이다. ${ }^{12)}$ 지역사회 거주하는 노인을 대상 으로 재활승마 운동 후 $\mathrm{BBS}$ 와 균형척도에서 유의한 차이가 있었으며, 재활승마 운동은 전정계 자극과 수직축 방향의 운 동 장점이 있어서 낙상 예방 위한 운동으로 유익하다. ${ }^{13)}$ 
Table 3. Comparison of balance and GQOL between groups

\begin{tabular}{|c|c|c|c|c|}
\hline \multicolumn{2}{|c|}{ Variables } & Experimental group(n=7) & Control group(n=7) & $\mathrm{p}$ \\
\hline \multirow{4}{*}{$\mathrm{WD}^{\mathrm{a}}$} & pre & $44.72 \pm 2.71$ & $45.51 \pm 1.56$ & \multirow{4}{*}{$0.001^{\dagger}$} \\
\hline & post & $48.62 \pm 1.14$ & $45,54 \pm 1.88$ & \\
\hline & diff & $3.90 \pm 2.61$ & $0.03 \pm 0.91$ & \\
\hline & $\mathrm{p}$ & $0.018^{\dagger}$ & 0.735 & \\
\hline \multirow{4}{*}{$\mathrm{WD}^{\mathrm{b}}$} & pre & $45.97 \pm 1.73$ & $45.75 \pm 2.03$ & \multirow{4}{*}{$0.001^{\dagger}$} \\
\hline & post & $48.90 \pm 1.05$ & $45.11 \pm 1.88$ & \\
\hline & diff & $2.93 \pm 1.60$ & $-0.64 \pm 0.98$ & \\
\hline & $\mathrm{p}$ & $0.018^{\dagger}$ & 0.128 & \\
\hline \multirow{4}{*}{$\mathrm{BBS}^{\mathrm{c}}$} & pre & $44.57 \pm 4.31$ & $44.71 \pm 4.34$ & \multirow{4}{*}{$0.001^{\dagger}$} \\
\hline & post & $48.28 \pm 1.60$ & $44.42 \pm 4.19$ & \\
\hline & diff & $3.71 \pm 3.30$ & $-0.29 \pm 1.11$ & \\
\hline & $\mathrm{p}$ & $0.018^{\dagger}$ & 0.102 & \\
\hline \multirow{4}{*}{ GQOL $^{\mathrm{d}}$} & pre & $68.42 \pm 8.14$ & $71.57 \pm 2.69$ & \multirow{4}{*}{$0.017^{\dagger}$} \\
\hline & post & $75.71 \pm 8.17$ & $70.85 \pm 2.96$ & \\
\hline & diff & $7.29 \pm 3.03$ & $-0.71 \pm 1.11$ & \\
\hline & $\mathrm{p}$ & $0.043^{\dagger}$ & 0.480 & \\
\hline
\end{tabular}

$W D^{a}$ :weight distribution(left-right), $W D^{b}:$ weight distribution(forward-backeard), $B B S^{c}$ :berg balance scale, GQOL':geriatric quality of life scale, * $p<0.05,{ }^{\dagger} p<0.01$

본 연구도 지역사회 거주하는 노인을 대상으로 재활승마 운동을 실시 한 후 $\mathrm{BBS}$ 의 유의한 차이가 있었고, 선행 연구 결과와 일치하였다. 말등 위에서 다양한 방향의 체간 움직임 을 통해 자세조절 능력이 향상된 결과라고 생각된다. 본 연구 의 재활승마 운동 후 $\mathrm{BBS}$ 의 유의한 차이의 결과는 주어진 환 경에서 자세조절의 동적, 정적 균형 능력 향상을 의미하며, 재 활승마 운동이 노인의 균형능력 향상 위한 운동으로 매우 탁 월한 효과가 있다고 판단된다. 본 연구는 노인을 대상으로 재 활승마 운동 전, 후 체간근 활성화에 대한 요인 분석을 하지 않았으나, 체간 안정성과 관련된 근활성에 대한 연구가 필요 하다고 생각된다.

재활승마 운동은 능동적 체중이동을 통해 신체 기능적 활 동을 위한 동적, 정적 균형 능력 향상에 긍정적이며, ${ }^{14)}$ 뇌성마 비 아동을 대상으로 재활승마 운동 후 왼쪽-오른쪽, 앞쪽-뒤쪽 체중지지 비율에서 유의한 차이가 나타났고, 체간과 골반의 대칭 자세가 향상 되었다. 이와 같은 결과는 말 위에서 앉은 자세를 유지하는 동안 체간근과 골반근 활성도가 증가하여 나 타난 결과이며, 재활승마는 균형 향상 위한 훈련 방법으로 매 우 효과가 있다. ${ }^{15)}$

본 연구에서도 노인을 대상으로 재활승마 운동 후 왼쪽-오 른쪽, 앞쪽-뒤쪽 체중지지 변화에서 유의한 차이가 있었고, 본 연구의 대상자와 선행연구의 대상자는 일치하지 않으나 재활
승마 운동 후 왼쪽-오른쪽, 앞쪽-뒤쪽 체중지지 비율에서 유의 한 변화는 선행연구 결과와 일치하였다. 자세조절의 제한은 기능적 활동에 장애가 되며, 선 자세와 보행 하는 동안 정적, 동적 균형 유지 위한 체중지지와 체중 이동은 기능적 활동에 매우 중요하다. 선행 연구의 재활승마 운동 후 뇌성마비 아동 의 균형능력 향상 효과는 균형 능력이 저하된 노인에게도 같은 효과가 있고, 말 위에 앉은 자세에서 다양한 방향으로 체중이 동 하는 동안 자세유지가 균형을 향상시킨 것으로 판단된다.

치매노인과 정상 노인을 대상으로 실내 승마기를 이용하여 평보단계로 운동을 한 후 균형 능력이 향상 되었으며, 낮은 강도의 재활승마 운동 이라도 지속적 운동이 노인 균형 향상 위한 운동으로 적절하고 정서적 안정에도 도움이 된다. ${ }^{16)}$ 노 인들은 젊은층에 비해 스포츠 활동에 적극 참여의 기회가 상 대적으로 적으며, 낮은 강도의 재활승마 운동이라도 흥미를 유발 시킬 수 있다. 그리고 유산소 운동과 심리적 안정에 효 과가 있다. ${ }^{17)}$ 신체 기능장애로 인해 정상적 사회관계를 유지 하지 못하는 경우 인간과 말의 의사 소통이 스트레스를 낮추 게 해준다. 이와 같이 재활승마는 노인의 균형 향상으로 자세 안정성과 스트레스를 감소시키어 노인 삶의 질척도를 증가시 킨다. ${ }^{5)}$

본 연구의 재활승마 운동 후 노인 삶의 질척도에서 유의한 차이가 있었다. 본 연구에 사용한 노인 삶의 질척도 설문지 
문항에서 행복, 희망 등의 긍정적 감정의 점수는 증가하였고 우울, 불안, 절망 등의 부정적 감정의 점수는 감소하여 재활승 마 운동 후 정서적 안정에 도움이 된 것은 선행연구의 결과와 일치하였다. 본 연구의 재활승마 운동은 실외에서 낮은 강도 로 짧은 기간 동안 실시하였으나, 노인 삶의 질척도에서 유의 한 차이가 나타난 것은 균형 향상이 영향을 미친 것으로 판단 된다. 노화에 따른 균형 저하는 낙상의 위험 요인이 되며, 낙 상 후 운동기능 장애와 움직임에 대한 두려움은 노인 삶의 질 에 많은 영향을 미친다. 실외에서 말을 매개로 하는 재활승마 는 균형 향상으로 삶의 질척도에 긍정적 영향을 미치고, 낙상 예방 위한 운동 방법이며, 다양한 스포츠 활동에 제한이 있는 노인에게 적극 추천한다. 본 연구의 제한점은 남자 노인만 대 상 자로 하였고, 대상자의 수가 적었으며. 재활승마 운동이 노 인의 인지와 낙상에 대한 연구가 필요하다고 생각된다.

\section{References}

1. Kwak IS. Study on family strength and happiness of the pre-elderly and the elderly. J Kore Home Econ Assoc, 2013;51(1):1-17.

2. Park SW. Sarcopenia of the old age. Endocrinology and metabolism. 2007;22(1):1-7.

3. Son NJ, Yi KO, An JY. The effect of exercise program for prevention of falling on physical fitness, posture and fall prevention self-efficacy for elderly women. J Kore Gerontol Soci. 2017;37(1):237-50.

4. Homnick DN, Henning KM, Swain CV, et al. Effect of therapeutic horseback riding on balance in community-dwelling older adults with balance deficits. J Altern Complement Med. 2013;19(7):622-6.

5. Lessick M1, Shinaver R, Post KM, et al. Therapeutic horseback riding. Exploring this alternative therapy for women with disabilities. AWHONN Lifelines. 2004;8(1):46-53.

6. Jee YS, Ko IG. The Therapeutic Effects of Horseback Riding (Hippotherapy). Kore J Exerc Rehab. 2012;8(3): 71-80.
7. All AC, Loving GL, Crane LL. Animals, horseback riding, and implications for rehabilitation therapy. J Rehab, 1999.

8. Lee DB. Influence on change of inflammatory markers in blood by therapeutic riding. Kore J Sport Sci. 2017;26(3):1059-67.

9. Lee SL, Kim DK, Ko HJ, et al. The standardization of geriatric quality oflLife scale. Kore J Clin Psych. 2003;22(4):859-81.

10. Olivier A, Faugloire E, Lejeune L, et al. Head stability and head-trunk coordination in horseback riders: The contribution of visual information according to expertise. Front Hum Neurosci. 2017;11(11):1-14.

11. Uchiyama H, Ohtani N, Ohta M. Three-dimensional analysis of horse and human gaits in therapeutic riding. Appl Anim Behav Sci. 2011;135:271-6.

12. Kim SG, Lee JH. The effects of horse riding simulation exercise on muscle activation and limits of stability in the elderly. Arch Geron and Geri. 2015;60:62-5.

13. Homnick TD, Henning KM, Swain CV, et al. The effect of therapeutic horseback riding on balance in community-dwelling older adults: a pilot study. J Appl Gerontol. 2015;34(1):118-26.

14. Jung TW, Cho HG, Park JY, et al. The Effects of therapeutic horse riding activities to balance of the children with cerebral palsy. Kore J Adap Phys Act. 2016;24(1):111-121.

15. Jung SH, Jung TW, Cho HG. The effects of horse riding activities on equilibrium and backbone posture of the children with cerebral pals. Kore J Adap Phys Act. 2011;19(2):79-90

16. Kim DH, Kim SJ, Bae SS, et al. The effect of indoor horseback-riding machine on the balance of the elderly with dementia. J Kore Soci Phys Med. 2008;3(4):235-246.

17. Kim MJ, Kim KS, Kim TY, et al. The effect of robot based horse riding simulator in perceived psychological factors and energy expenditure for the elderly. KINESIOLOGY. 2015;17(4):21-9. 